\title{
Fluid Flow and Static Structural Analysis of E-glass Fiber Reinforced Pipe Joints versus S-glass Fiber Reinforced Pipe joints
}

\author{
Sujith Bobba ${ }^{a *}$, Z. Leman ${ }^{a, b}$, E.S. Zainuddin ${ }^{a}$ and S.M. Sapuan ${ }^{a, b}$ \\ ${ }^{a}$ Department of Mechanical and Manufacturing Engineering, Faculty of Engineering, Universiti Putra Malaysia, 43400 \\ +Serdang, Malaysia. \\ ${ }^{b}$ Laboratory of Biocomposite Technology, Institute of Tropical Forestry and Forest Products (INTROP), Universiti \\ Putra Malaysia, 43400 Serdang, Malaysia.

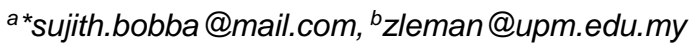

\begin{abstract}
:
Filament wound composite pipes are frequently used in the field were transmission of high pressured chemical fluids, disposal of industrial wastes, oil and natural gas transmission takes place. In oil and gas industry, the pipelines transporting heavy crude oil are subjected to variable pressure waves causing fluctuating stress levels in the pipes. Computational Fluid Dynamics Analysis was performed using Ansys 15.0 Fluent software to study the effects of these pressure waves on some specified joints in the pipes. Depending on the type of heavy crude oil being used, the flow behavior indicated a considerable degree of stress levels in certain connecting joints, causing the joints to become weak over a prolonged period of use. In this research comparison of various pipe joints was done by using different material and the output result of the stress levels of the pipe joints were checked so that the life of the pipe joints can be optimized by the change of material.
\end{abstract}

Keywords: Computational fluid dynamics; Glass fiber reinforced composites; Heavy crude oil; Pressure waves

\section{INTRODUCTION:}

The most frequently used pipe systems for fluid transport are made of glass fiber reinforced plastic composites, also known as fiberglass composites. In other words, infrastructural industries can be considered as the pioneer for exploiting composite materials in preventing corrosion in chemically reactive environments and its consequent repair costs are the main reasons that different industrial sections have been encouraged to employ glass fiber reinforced plastic pipes [1]. glass fiber reinforced plastic pipes and pipe joints are implemented to remain in operation for 60 years as a long-term design constraint regulated by international rules and regulations [2,3]. Almost all conducted studies in the literature on characterizing design behavior of glass fiber reinforced plastic pipes subjected to internal pressure have been carried out experimentally $[4,5]$ but not on pipe joints where the flow is turbulent.

Subsea pipe line system is used to connect the offshore production platforms to onshore production platforms. Inspection of the pipe line system is done on regular basis but in few cases where the danger is not predicted the failure of the system may occur. Many researchers have worked on the prediction and control of sudden failure.

\subsection{Analysis of historic pipe joint failures:}

Pipe failures are caused by applied forces which exceed the general residual strength of the pipe material. Pipe breakage occurs when the stresses of both operational and environmental act on pipes where 
corrosion, degradation, inadequate installation or manufacturing defects have impacted the pipes structural integrity. The physical mechanisms of failures in pipes are usually a complex function of many contributing factors. This includes pipe properties such as material, size, internal and external loadings and environmental factor [6]. Consequently, various other failure localities can be observed including joint connection failure, brittle failure, split pipe, transverse break, graphitization, pitting holes, longitudinal, circumferential failures spiral cracking, and blowout hole. When comparing the factors for failure, physical characteristics such as material type, size and temperature have been identified as the most important factors.

In the case of structural stress anaylsis Xia $\mathrm{M}$ et al. [7] have found out two methods to evaluate stresses and deflections of filament wound pipe joints which were subjected to transverse loading using curved composite-beam and multi-layer build-up theories. Various studies were conducted on glass fiber reinforced plastic pipe's mechanical properties and failures such as bending[8] , transverse loading[9,10] , axial compression[11,12] and internal pressure loading conditions were conducted regularly.

\subsection{Impact of pressure fluctuation on pipe joint failure:}

The term pressure fluctuation is used to express any change in pressure level inside the pipe lines, either it is a slow change in the day to day pressure profile or immediate changes in pressure transient events. These tend to have a repeating pattern, even though there might be much variation in the frequency, magnitude and shape of each event. In addition, separation of pressure fluctuation profiles from other profile on a sudden phase can be highly difficult. However, there have been only few past studies on the failure mechanism of pipe lines when they are exposed to frequent cycles of pressure fluctuations. In practice, common pipe lines across a crude oil distribution network will be unprotected to varying pressure during daily and seasonal variation of oil extraction as well as due to changes in operation of the system. Similar to sudden pressure changes, the relationship between (gradual) pressure variation and mains failure is not well understood.

The flow area sometimes can be blocked due to the displacement of successive layers (fiber/matrix) of the material and the brust pressure of the pipe joint increases due to block and the failure might occur. The influence of impact failure due to burst pressure can be evaluated by decreasing the burst pressure and increasing impact energy as per the studies done by various researchers[13].

\section{DESIGN OF THE PIPE JOINTS:}

It should be pointed out that all designed glass-reinforced plastic, glass reinforced vent and glass reinforced epoxy pipes with filament winding process have the same pipe wall construction and thickness. But, for the case of GRV and GRE pipes, most often pure GFRP layers are used and sand layer is palced into GRP pipes for the water or waste water transmission applications and also in some cases reduction of the wall thickness is often the intial stage of failure events, since it produces local stress concentration. For the analysis part of the pipe joints such as T-joint, elbow joint, four way joints design are done as per ASME B31.3 Process Piping Code [14] with $94.6 \mathrm{~mm}$ inner diameter, $100 \mathrm{~mm}$ outer diameter , thickness of the pipe is $5.4 \mathrm{~mm}$, radius of curvature of $75 \mathrm{~mm}$ and $100 \mathrm{~mm}$ longitudinal length on each side of the joint as shown in the fig.1. The material used is one with E-glass fiber and another with S-glass fiber. The material properties of S-Glass and E-glass used for design are shown in Table 1. 


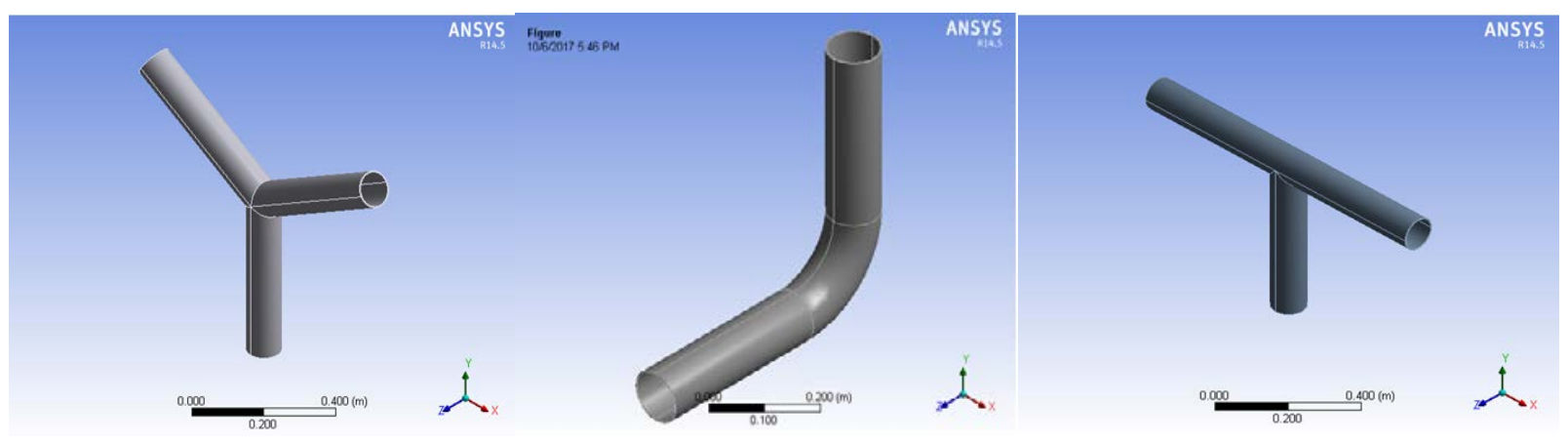

Figure-1: Design of pipe joints with required dimensions in Ansys 15.0 Work bench

Table-1: Material properties of S-Glass and E-glass used for design

\begin{tabular}{|c|c|c|c|}
\hline S.No & Property & S-Glass & E-Glass \\
\hline 1 & Density & $2.49 \mathrm{~g} / \mathrm{cm}^{3}$ & $2.55 \mathrm{~g} / \mathrm{cm}^{3}$ \\
\hline 2 & Possion's ratio & 0.22 & 0.22 \\
\hline 3 & Shear Modulus & $37 \mathrm{GPa}$ & $34 \mathrm{GPa}$ \\
\hline 4 & Young's Modulus & $89 \mathrm{GPa}$ & $79 \mathrm{GPa}$ \\
\hline 5 & Compression strength & $4500 \mathrm{MPa}$ & $4500 \mathrm{MPa}$ \\
\hline 6 & Tensile strength & $4750 \mathrm{MPa}$ & $2000 \mathrm{MPa}$ \\
\hline
\end{tabular}

\section{RESULTS AND DISSCUSION:}

\subsection{Flow Analysis of the Pipe Joints:}

Various models $[15,16]$ based on this method including physically based methods require significant data and usually costly investigations on the pipe joint's deterioration processes, so flow analysis would be a source for an imaginary view of the failures before installation of the pipe joints in the pipeline system. Since the pressure flow is maximum at the joints. Comparison of flow analysis between E-glass material and S-glass material has been done.

Table 2: Heavy Crude Oil Parameters for Flow Analysis

\begin{tabular}{|c|c|}
\hline Property & Value in Units \\
\hline Specific heat & $1970 \mathrm{~J} / \mathrm{kg}$ at $273.16 \mathrm{~K}$ \\
\hline Molecular mass & $0.5 \mathrm{~kg} / \mathrm{mol}$ \\
\hline Dynamic viscosity & $0.0011233 \mathrm{pa} / \mathrm{s}$ at $273.16 \mathrm{~K}$ \\
\hline Thermal conductivity & $0.522 \mathrm{~W} / \mathrm{m}$ at $273.16 \mathrm{~K}$ \\
\hline Specific heat ratio & 1.2 \\
\hline
\end{tabular}


Table 3: Thermodynamic Parameters for Flow Analysis

\begin{tabular}{|c|c|}
\hline Parameter & Value in Units \\
\hline Pressure & $19432.5 \mathrm{~Pa}$ \\
\hline Temperature & $273.5 \mathrm{~K}$ \\
\hline Density & $970 \mathrm{~kg} / \mathrm{m}^{3}$ \\
\hline
\end{tabular}

Table 4: Number of elements and nodes for each joint after meshing done on the per fined pipe joints

\begin{tabular}{|c|c|c|c|c|}
\hline S.No & Type of Joint & Domain & Nodes & Elements \\
\hline 1 & Elbow-Joint & Solid & 3135 & 2484 \\
\hline 2 & T-Joint & Solid & 4792 & 21278 \\
\hline 3 & Y-Joint & Solid & 4730 & 21376 \\
\hline
\end{tabular}

\subsubsection{Flow pressure comparison in E-glass elbow joint and S-glass elbow joint:}

Elbow joint with E-glass and S-glass have equal maximum pressure of $110.3 \mathrm{~Pa}$ from the CFD analysis and minimum pressure of -727.7 Pa from the CFD analysis shown below in the fig.2.

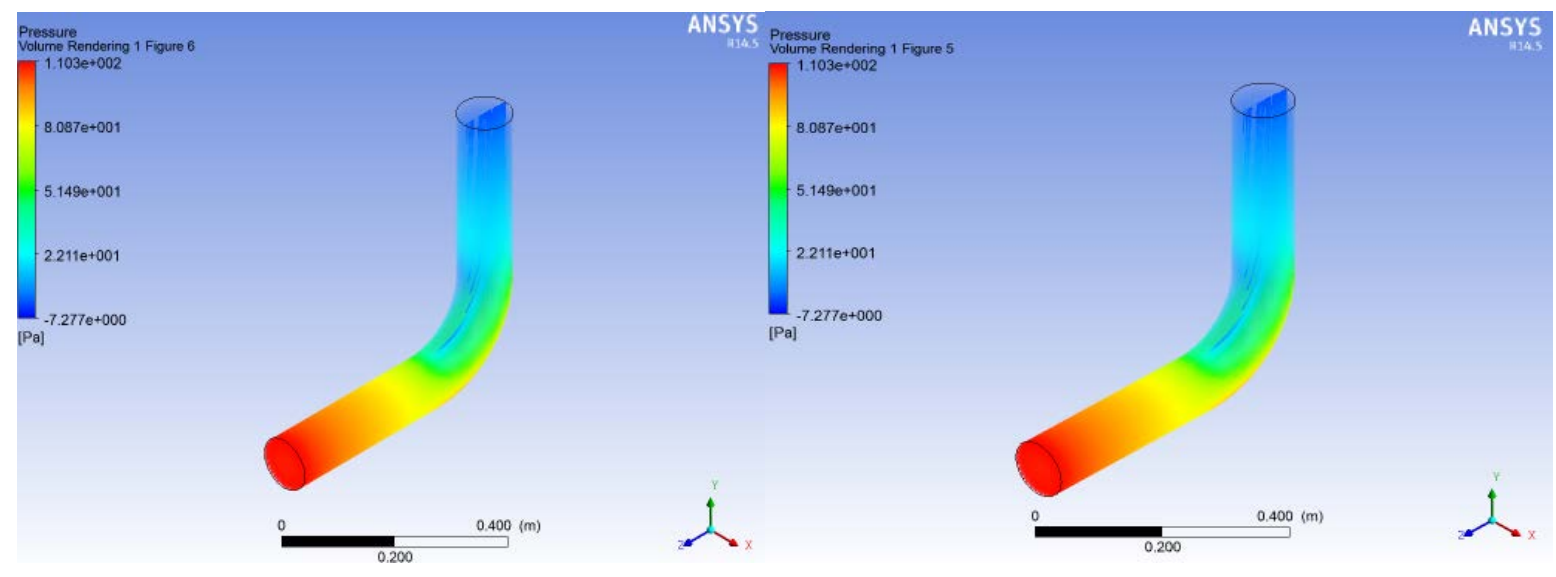

Figure 2 : Comparsion of pressure fluacation between E-glass elbow joint and S-glass elbow joint through CFD analysis

\subsubsection{Flow Pressure comparison in E-glass $Y$-joint and S-glass $Y$-Joint:}

Y-joint made with E-glass and S-glass have equal maximum pressure of $122.1 \mathrm{~Pa}$ from the CFD analysis and minimum pressure of $-118.4 \mathrm{~Pa}$ from the CFD analysis shown below in the fig.3. 


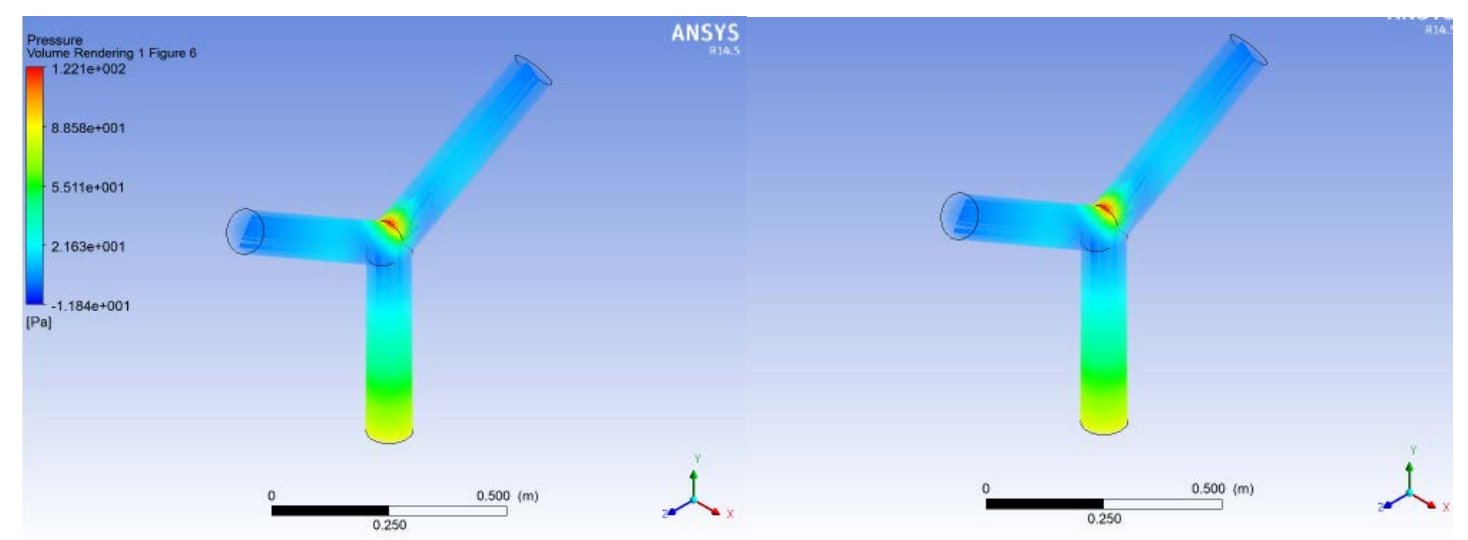

Figure 3 : Comparsion of pressure fluacation between E-glass $Y$-joint and S-glass $Y$-joint through CFD analysis

\subsubsection{Flow pressure comparison in E-glass T- joint and S-glass T- Joint:}

T- joint with E-glass and S-glass have equal maximum pressure of 147.6 Pa from the CFD analysis and minimum pressure of -108.7 Pa from the CFD Analysis shown below in the fig. 4 .

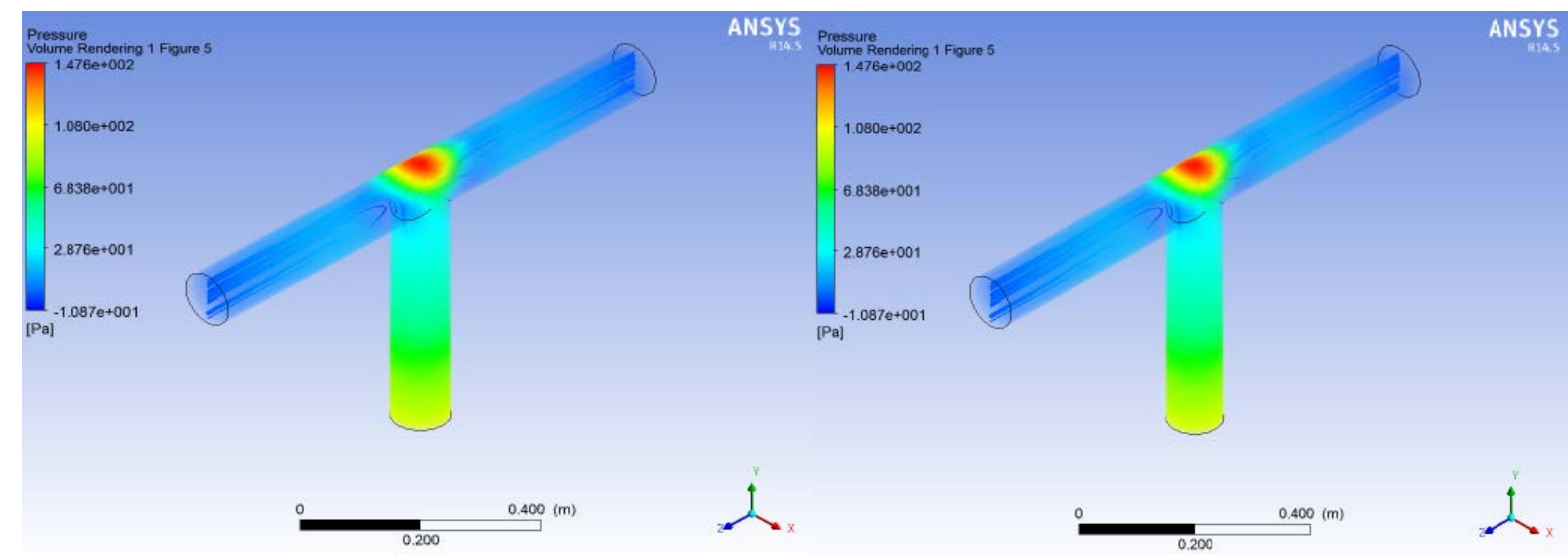

Figure -4 : Comparsion of pressure fluacation between E-glass T-joint and S-glass T-joint through CFD analysis

Table-5 :Maxiumum and Minimum pressure flow in the Pipe joints

\begin{tabular}{|c|l|c|c|}
\hline S.No & Type of Joint & \multicolumn{2}{|c|}{ Pressure Flow } \\
\hline & & Maximum & Minimum \\
\hline 1 & Elbow joint(S-Glass/E-Glass) & $110.3 \mathrm{~Pa}$ & $-727.7 \mathrm{~Pa}$ \\
\hline 2 & Y-Joint(S-Glass/E-Glass) & $122.1 \mathrm{~Pa}$ & $-118.4 \mathrm{~Pa}$ \\
\hline 3 & T-Joint(S-Glass/E-Glass0 & $147.6 \mathrm{~Pa}$ & $-108.7 \mathrm{~Pa}$ \\
\hline
\end{tabular}

Finally after the flow analysis it was concluded that pipe joint ending condition has much influence on the pressure surge propagation of the pipe joint

\subsection{Static Structural Analysis of the Pipe Joints:}

\subsubsection{Equivalent (von Mises) Stress:}


Considering the maximum pressure obtained from the flow analysis of each pipe joint shown in the Table5.Static structural and theoretical calculation to find the von Mises stress was performed and compared

To calculate the equivalent von Mises stress [17]:

$$
\begin{gathered}
\sigma_{1} \text { (Hoop Stress) }=\frac{P_{d}}{2 \mathrm{~T}} \\
\sigma_{2} \text { (Radial Stress) }=-\mathrm{P} *\left(\mathrm{ri}_{\mathrm{i}}\right)^{2}\left(\mathrm{ro}_{\mathrm{o}}\right)^{2}-\mathrm{r}^{2} * \mathrm{r}^{2} *\left(\mathrm{ro}^{2}-\mathrm{ri}^{2}\right) \\
\sigma_{y}(\text { Von Mises })=\sqrt{\sigma 1^{2}+\sigma 2^{2}-2 \sigma 1 \sigma 2}
\end{gathered}
$$

Where,

$\mathrm{P}_{\mathrm{d}}=$ Maximum Pressure

$r_{i}=$ Inner Radius of the pipe joint

$r_{o}=$ Outer Radius of the pipe joint

$\mathrm{r}=$ Radius of curvature of the pipe joint.

By performing theoretical calculation the following results shown in the Table- 6 are obtained

Table-6: Maximum pressure flow by therotical calucations in the pipe joints :

\begin{tabular}{|c|l|c|c|}
\hline S.No & Type of Joint & S-glass & E-glass \\
\hline 1 & Elbow joint & $87.904 \mathrm{~Pa}$ & $88.924 \mathrm{~Pa}$ \\
\hline 2 & Y-joint & $85.45 \mathrm{~Pa}$ & $97.45 \mathrm{~Pa}$ \\
\hline 3 & T-joint & $129.72 \mathrm{~Pa}$ & $136.72 \mathrm{~Pa}$ \\
\hline
\end{tabular}

\subsubsection{Finite element analysis of the pipe joints:}

Static analysis is carried out in order to find the sorted code stresses, code compliance stresses, pipe support load, element forces and moments (in local and global coordinates), the data for performing structural analysis of the pipe joints is shown in the Table 7 and the number of elements and nodes for each joint are shown in the Table 4.

\subsubsection{Equivalent (von Mises) Stress of E-glass and S-glass Elbow joint:}

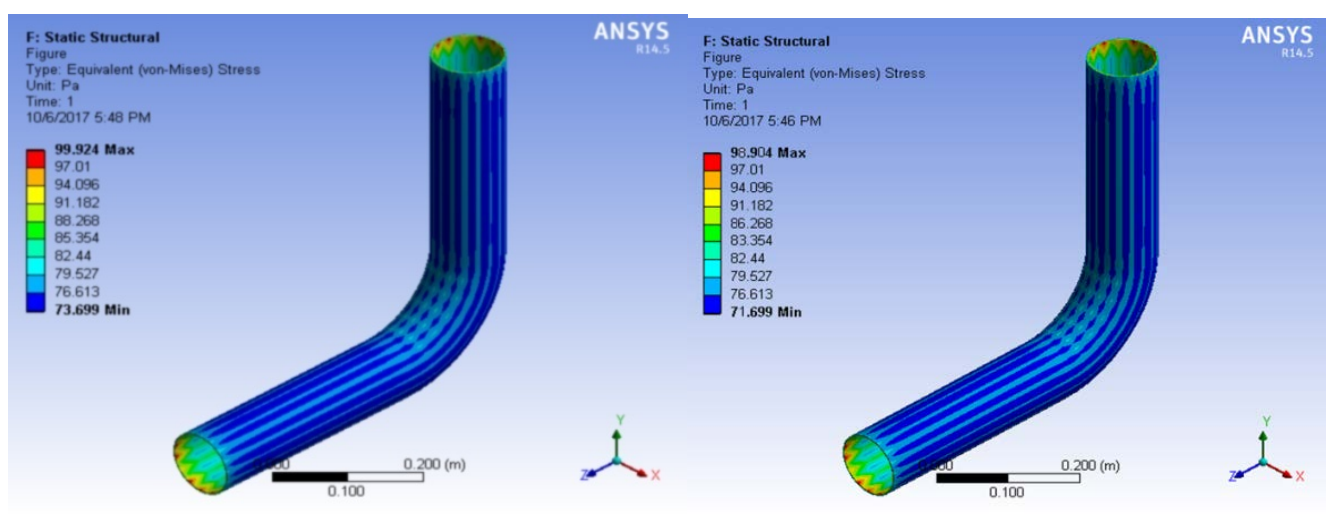


Figure 5: Contours of von Mises equivalent stress during 100\% crude oil flow with maximum pressure in the elbow joint

The maximum value of the von Mises equivalent stress of E-glass elbow joint is $99.924 \mathrm{~N} / \mathrm{m}^{2}$ and that of Sglass is $98.904 \mathrm{~N} / \mathrm{m}^{2}$.

\subsubsection{Equivalent (von Mises) Stress of E-glass and S-glass Y-joint:}

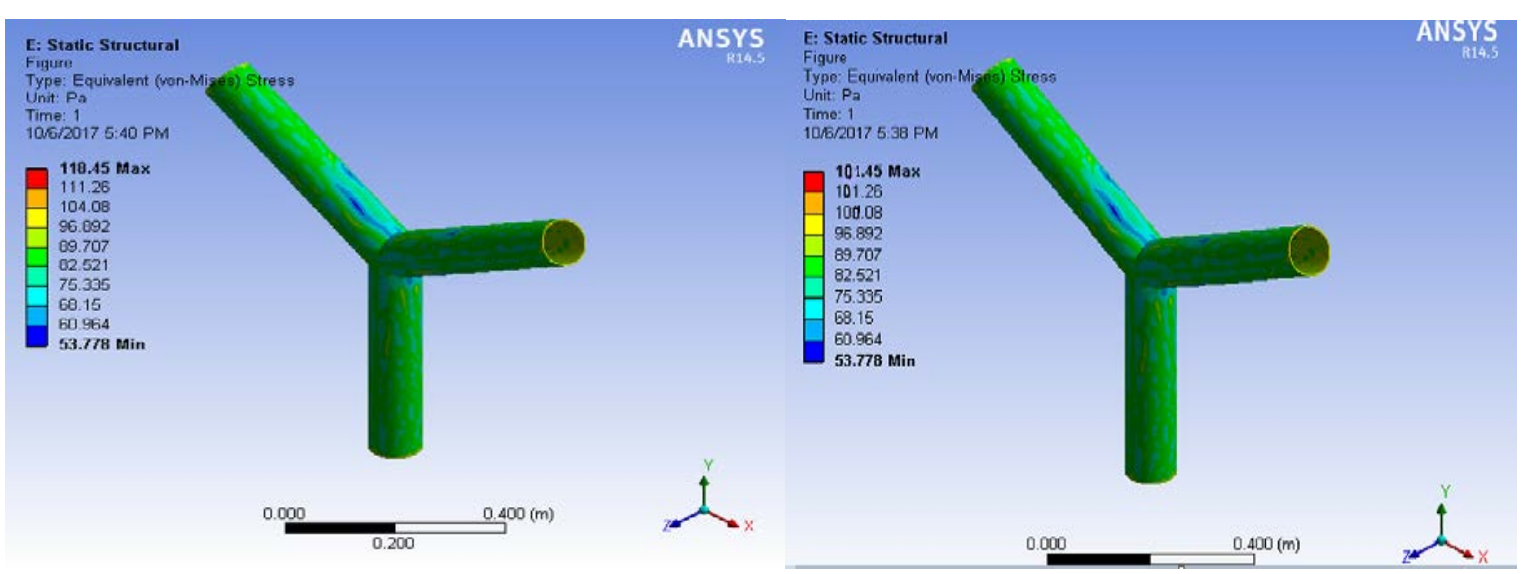

Figure 6: Contours of von Mises equivalent stress during 100\% crude oil flow with maximum pressure in the $Y$ - joint

The maximum value of the von Mises equivalent stress of E-glass Y-joint is $118.45 \mathrm{~N} / \mathrm{m}^{2}$ and that of Sglass is $101.45 \mathrm{~N} / \mathrm{m}^{2}$.

\subsubsection{Equivalent (von Mises) Stress of E-glass and S-glass T-joint:}

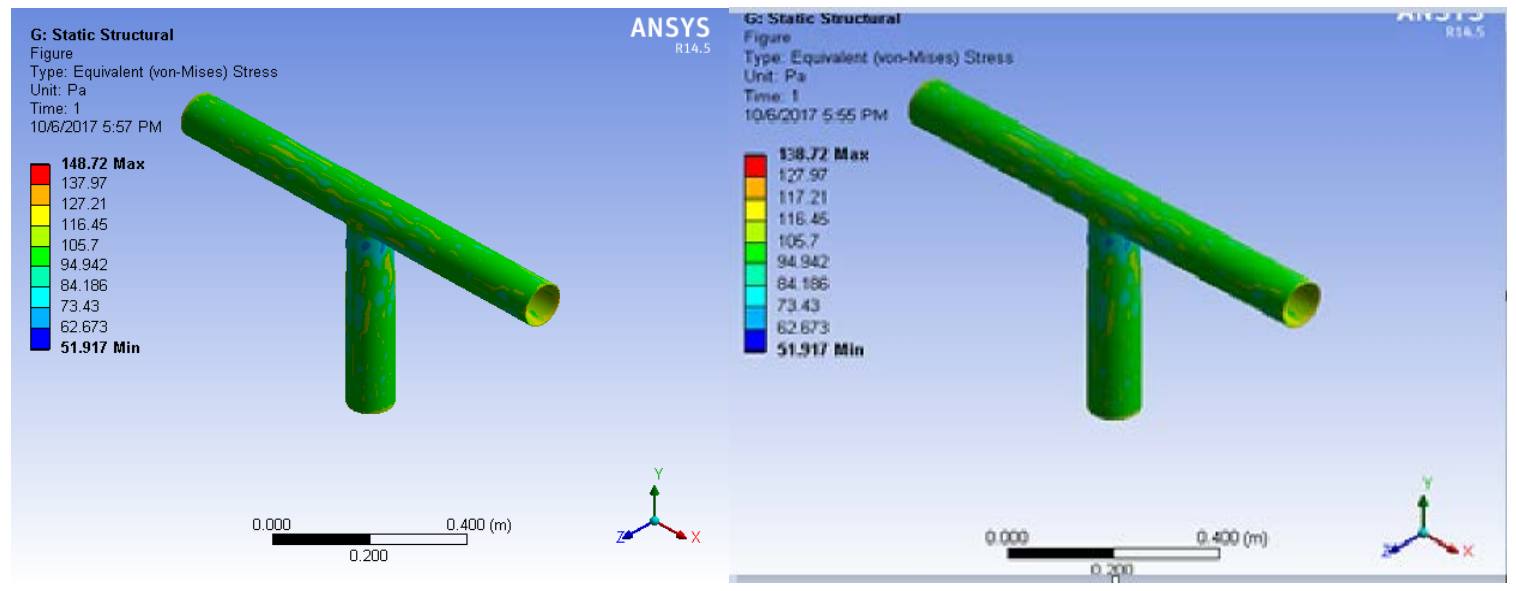

Figure 7: Contours of von Mises equivalent stress during 100\% crude oil flow with maximum pressure in the $T$ joint

The maximum value of the von Mises Equivalent stress of E-glass T-joint is $148.72 \mathrm{~N} / \mathrm{m}^{2}$ and that of Sglass is $138.72 \mathrm{~N} / \mathrm{m}^{2}$. 
Table 7: Maximum equivalent (von Mises) and minimum equivalent (von Mises) Stress of Various Joints with E-glass and S-glass Fiber material:

\begin{tabular}{|c|c|c|c|c|}
\hline S.No & Type of Joint & & S-Glass & E-Glass \\
\hline \multirow[b]{2}{*}{1} & \multirow[b]{2}{*}{ Elbow joint } & Maximum & $98.904 \mathrm{~Pa}$ & $99.924 \mathrm{~Pa}$ \\
\hline & & Minimum & $73.699 \mathrm{~Pa}$ & $71.699 \mathrm{~Pa}$ \\
\hline \multirow[b]{2}{*}{2} & \multirow[b]{2}{*}{ Y-joint } & Maximum & $101.45 \mathrm{~Pa}$ & $118.45 \mathrm{~Pa}$ \\
\hline & & Minimum & $53.778 \mathrm{~Pa}$ & $53.770 \mathrm{~Pa}$ \\
\hline \multirow[b]{2}{*}{3} & \multirow[b]{2}{*}{$\mathrm{T}$-joint } & Maximum & $138.72 \mathrm{~Pa}$ & $148.72 \mathrm{~Pa}$ \\
\hline & & Minimum & $51.917 \mathrm{~Pa}$ & $51.917 \mathrm{~Pa}$ \\
\hline
\end{tabular}

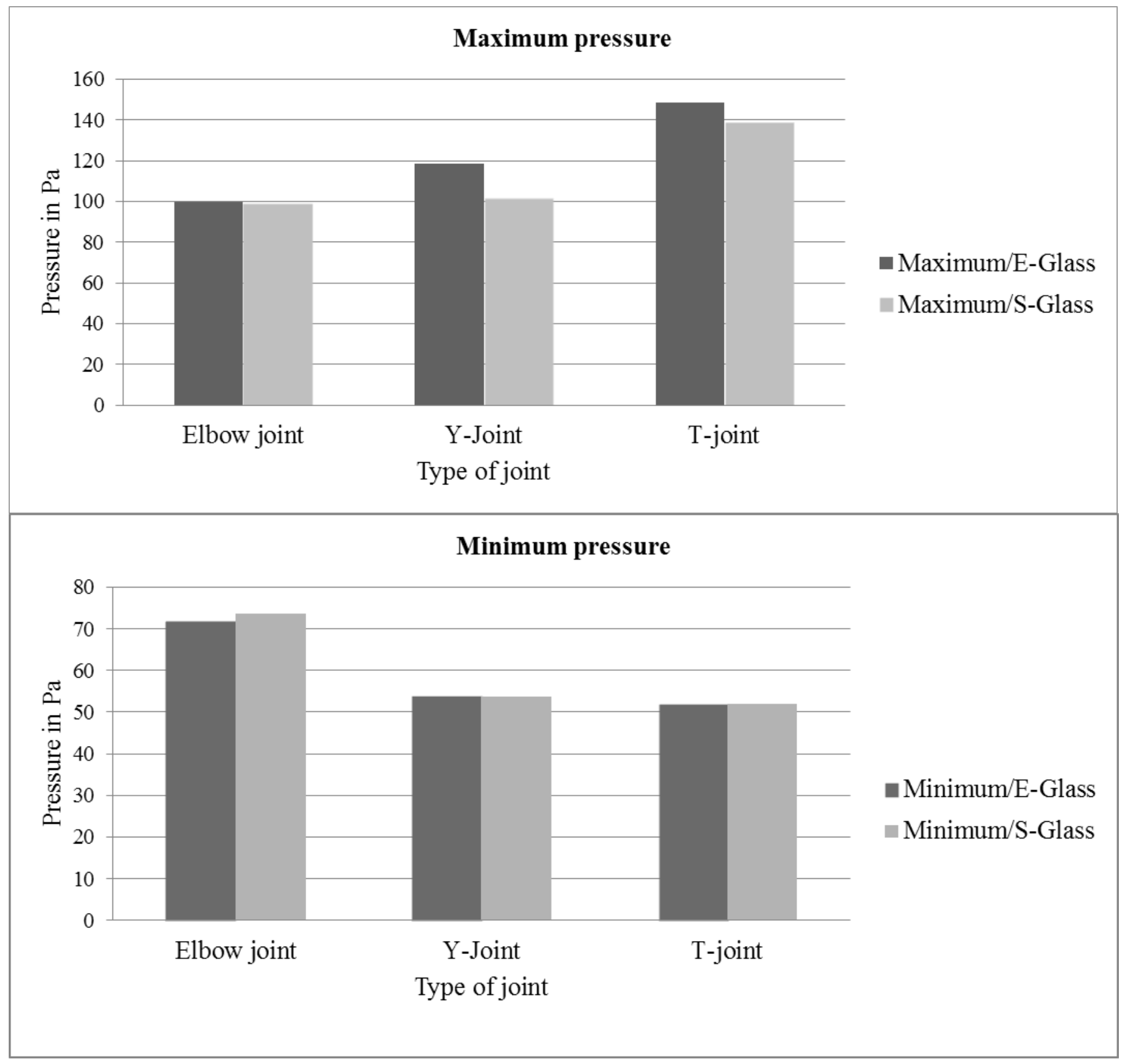

Figure 8: Maximum equivalent (von Mises) and minimum equivalent (von Mises) Stress of Various Joints with E-glass and S-glass Fiber material 
So when comparing the results obtained from the Ansys 15.0 Structural Analysis and theoretical calculation the percentage of accuracy are within the permissible limits of the yield strength of the pipe joints, so the design is safe for all the pipe joints.

Since the paper only concentrates on analysis part only material property of E-Glass and S-glass were considered and compared but when it comes to the fabrication part, with E-glass cloth, epoxy resin is coated by hand layup process but in the case of S-glass material, a coating of N-Matrix type resin Ndiglycidyltribromoanline (DGTBA) cross linked with metaphenylene diamine (MPDA) is proposed for fabrication, since it has good residual fatigue life as per the tests carried out by Romans et al [18].

\section{CONCLUSION AND RECOMMENDATIONS:}

There have been various studies on the failure mechanisms in pipe joints and their root causes other than pressure variation, material selection but as per the study done due to the turbulence flow in the pipeline the velocity gradients near the pipe joints have quite large shear and flow and structural analysis done S-glass fiber reinforced pipe joints have exibited better compressive and flexural behaviour than E-glass Fiber reinforced pipe joints. The results of the structural stress levels indicated that joints made with S-glass material would with stand for more life time than joints made of E-glass material and also the difference between simulation and theoretical results can logically be even $100 \%$ and it is supported by the results obtained and also the results obtained are less than maximum yield strength.

Finally at the glance, it is that by doing stress analysis it makes use possible to evaluate the results before preceding into the laboratory works and also by implementing S-glass material in the perfined joints rather tahn E-glass material enhances the durability of composite pipe in the long time run .They are also other reasons for the failures in glass fiber reinforced pipelines which may be due to environmental and physical conditions, but as per the research perspective only flow analysis was done.

\section{REFERENCES}

[1] L.C. Hollaway, A review of the present and future utilization of FRP compositesin the civil infra structure with reference to their important in-service properties, Constr. Build. Mater. 24 (2010) 24192445.

[2] AWWA Manual M45, Fiberglass Pipe Design ,second ed., American Water Works Association, Denver, 2005.

[3] ANSI/AWWA C950-01, Standard for Fiberglass Pressure Pipe, American Water Works Association, Denver, 2001.

[4] M.S. Abdul Majid, A.G. Gibson, M. Hekman, M. Afendi, N.A.M. Amin, Strain response and damage modelling of glass/epoxy pipes under various stress ratios, Plast. Rubber Compos. (2014) 290-299.

[5] D. Gay, S.V. Hoa, S.W. Tsai, Composite Materials: Design and Applications, CRC, Press, 2002.

[6] D. Linkens, N.K. Shetty, M. Bilo, A probabilistic approach to fracture assessment of onshore gastransmission pipelines, Pipes Pipelines Int. 43 (1998) 5-16

[7] Xia M, Takayanagi H, Kemmochi K. Analysis of transverse loading for laminated cylindrical pipes. Compos Struct 2001;53(3):279-85.

[8] Akkus N, kawahara M.Bending behaviors of thin composite pipes with reinforcing nodes. Mater Sci Res Int 2000;6:13l-5.

[9] Alderson KL, Evans KE. Failure mechanisms during the trans- verse loading of filament-wound pipes under static and low velocity impact conditions. Composites 1992;23:167-73. 
[10] Nishiwaki T, Yokoyama A, Maekawa Z, Hamada H, Mori S. A quasi - three-dimensional lateral compressive analysis method for a composite cylinder. Compos Struct 1995;32:293-8.

[11] Onoda Y. Optimal laminate configurations of cylindrical shells for axial buckling. AIAA J 1985;23(7):1093-8.

[12]Smerdov AA.A computational study in optimum formulation of optimization problems on laminated cylindrical shells for buckling: I.Shells under axial compression. Compos Sci Technol 2000;60:2057-66 [13] Quamrul H, Mazumder, CFD Analysis of the effect of elbow radius on pressure drop in Multiphase Flow , University of Michigan - Flint, MI, 48502, USA

[14] D. N. Veritas, Management System Certificate, ISO 9001:2008, 2008

[15] Y. Kleiner, B. Rajani, Comprehensive review of structural deterioration of water mains: statistical models, Urban Water. 3 (2001) 131-150.doi:10.1016/S1462-0758(01)00033-4.

[16] B. Rajani, Y. Kleiner, Comprehensive review of structural deterioration of water mains: physically based models, Urban Water. 3 (2001) 151-164. doi:10.1016/S1462-0758(01)00032-2.

[17] www.pysiscsforums.com, retrieved on 02 August 2017.

[18] Romans, J.B., Sands, A.G. and Cowling, J.E. Industrial and Engineering chemistry product research and Development, Vol 11, 1972, p 3. 